

\title{
CONCEPÇÕES PEDAGÓGICAS DA EDUCAÇÃO FÍSICA NO ENSINO MÉDIO
}

\author{
Thiago Mecenas Silva do Amor Divino ${ }^{1}$ \\ Maria Tatiane Santos Santana ${ }^{2}$
}

\section{RESUMO}

O presente artigo tem como objetivo apresentar algumas abordagens pedagógicas sobre a cultura corporal na educação física aplicada à alunos no ensino médio, uma vez que aos alunos nesse nível de ensino é importante considerar sua formação social, histórica e cultural no seu contexto de vida atrelado ao corpo e suas práticas de aprendizagem. Estas que devem ser experienciadas, vivenciando-as e respeitando ao que eles trazem em seu cotidiano. Se tem como metodologia no estudo, quanto aos seus objetivos, a pesquisa bibliográfica, esta que a partir de fontes já consultadas busca corresponder o contexto teórico dissertado à sua utilidade acadêmica e materialização do seu uso pela discussão apresentada. Assim respaldam essa discussão, Souza (2002), Kunz (1994), Piccolo, (1995) e Darido, (2001), entre outros autores; estes com fundamentações salutares para que se tenha uma nova compreensão da atuação docente nas escolas. Nesta discussão se suscitam resultados, teóricos de paradigmas entre novas fundamentações pedagógicas para a prática da Educação Física inovadora e a tradição metodológica tão comum nas práticas docentes. Neste aspecto sublima-se ser necessário aos professore a constante busca de seu papel no âmbito da educação física escolar, assim como em sua intervenção no meio social através da materialização da aprendizagem dos alunos.

Palavras- chave: Abordagens pedagógicas. Educação física. Ensino médio. Cultura Corporal.

\footnotetext{
${ }^{1}$ thiagomecenas@hotmail.com.

${ }^{2}$ santanatatiane2011@ hotmail.com.
} 


\section{RESUMEN}

Este artículo tiene como objetivo presentar algunos enfoques pedagógicos sobre la cultura corporal en la educación física aplicado a estudiantes en en la escuela secundaria, ya que los estudiantes en este nivel de educación son importantes para considerar sus antecedentes sociales, históricos y culturales en su contexto de vida vinculado al cuerpo y sus prácticas. de aprendizaje. Estos deben ser experimentados al experimentarlos y respetar lo que aportan en su vida diaria. Si la metodología en el estudio se basa en sus objetivos, la investigación bibliográfica, que a partir de fuentes ya consultadas, busca igualar el contexto teórico dirigido a su utilidad académica y materialización de su uso por la discusión presentada. Por lo tanto, apoye esta discusión, Souza (2002), Kunz (1994), PIiccolo, (1995) y Darido, (2001), entre otros maestros; con una base saludable para una nueva comprensión del desempeño docente en las escuelas. En esta discusión se plantean los resultados, paradigmas teóricos entre nuevos fundamentos pedagógicos para la práctica de la Educación Física innovadora y la tradición metodológica tan común en las prácticas docentes. En este aspecto, se enfatiza que es necesario que el maestro busque constantemente su papel en el contexto de la educación física en la escuela, así como en su intervención en el entorno social a través de la materialización del aprendizaje del alumno.

Palabras clave: pedagógicas. Educación Física. Escuela secundaria. Cultura del cuerpo. 


\section{INTRODUÇÃO}

Sobre as mudanças advindas da Lei de Diretrizes e Bases da Educação, (LDB), promulgada no dia 20 de Dezembro de 1996, em seu art. 26 inciso III que considera a educação física como componente curricular, nela se observa que a prática de educação física no ensino médio apresenta problemas principalmente no que se refere as questões pedagógicas, ou seja, infere haver uma suposta dificuldade de entendimento da educação física como componente curricular e uma seleção de conteúdos altamente desarticulados. Isso é corroborado por Werrneck (1992) ao citar que existe na educação: "A política do fingimento, ou seja, o professor finge que ensina e o aluno finge que aprende". (WERRNECK,1992, p. 28). Assim vem se percebendo que há um grande distanciamento do cumprimento do que vem citando a LDB.

Se tem como objetivo geral deste estudo apresentar nuances pedagógicas sobre a educação física no ensino médio consolidando-as à cultura corporal préexistente nos alunos e na correlação disso com suas práticas diárias e a própria aprendizagem. Entre os objetivos específicos do estudo estão conhecer algumas práticas pedagógicas inerentes ao ensino da educação física no ensino médio atreladas a sua função cultural, social e de aprendizagem dos alunos.

Os estudiosos (SOUZA, 2002, Apud, GIROUX, 1986, p.3) comentam sobre as dificuldades existentes acerca das mudanças em educação que podem estar atreladas a questão da resistência ou flexibilidade nas práticas pedagógicas que se vinculam à mecanismos de reprodução cultural que impedem ocorrer "[...] nesses espaços de resistência que devem ser construídas novas práticas pedagógicas desenvolvendo estratégias em escola nas quais os alunos de oposição poderiam fornece a base para uma força política viável." Assim acredita-se que a resistência deva existir como um espaço de lutas onde acontece a mudança do pensar, sentir e agir e com isso as possíveis transformações sociais.

Para Souza (2002) a educação física, situada na escola tem como função o resgate e a contribuição de saberes que se vinculam à cultura corporal e devem ser somados à perspectiva de formação educacional. No entanto, para Souza (2002), os conhecimentos tratados nas metodologias do seu tempo já vinham reproduzindo uma ordem social vigente colaborando com uma escola inviabilizadora à novos conhecimentos e habilidades necessárias às lutas por espaço social de modo competitivo e com equidade de conhecimentos. Neste sentido a escola não tem se moldado ao 
reconhecimento dos alunos enquanto seres competitivos para o ambiente social.

A justificativa deste estudo se dá pela possibilidade de discutir a importância da educação física no ensino médio e sua melhor compreensão no que se refere aos principais problemas da cultura corporal dos alunos envolvendo as práticas docentes. Neste aspecto é válido a produção de conhecimento científico convergindo ao enriquecimento didático e metodológico do ensino da educação física no ensino médio possibilitando ao profissional da área conduzir a sua intervenção com uma visão ampla sobre sua ação pedagógica.

\section{Abordagens pedagógicas para o ensino da educação física no ensino médio}

Baseando-se nas escritas do PCN's em Brasil (1999), a educação física no ensino médio tem como importância contribuir processualmente nos conhecimentos educacionais formais desenvolvendo uma visão geral do ensino a perspectiva da cultura corporal. Porém, por diversos estudos, entre eles, Piccolo(1995), a educação física e produtivista, mas excludente e limitada à prática dos esportes coletivos mais populares; assim adota uma prática que não dá espaço para o aluno se expressar ou criar, que chega pronta, projetada, ou seja, é uma
[...] prática é muito diferente da educação física auto crítica e passiva que acontece na realidade, isto é, os discursos educacionais e equivalem aos resultados observáveis. O que se espera é que as ações pedagógicas sejam coerentes com o pensamento pedagógico. Não se pretende com isso eliminar o desporto das escolas, mas não se pode considerar treinamento com a educação física escolar. (PICCOLO,1995, p. 11).

Definir o papel da educação física na escola não é tarefa fácil conforme alguns autores como Kunz (1994), o qual acredita que o papel da educação física na escola é de promover uma educação interativa e emancipadora, voltada à cidadania dos jovens, e não para uma mecânica prática de “[...] instrumentalização teórica para o trabalho. Deseja ainda introduzir com competência e organização a formação do indivíduo crítico com perspectiva emancipada." (KUNZ, 1994, p. 142).

Para Freire (1994) em relação a função pedagógica da educação física é:

[...] Atuar como qualquer outra disciplina da escola e não desintegrada dela. As habilidades motoras precisam ser desenvolvidas, sem dúvidas, mas deve estar claro quais serão as consequências desse ponto de vista cognitivo social e efetivo. Sem tornar disciplina auxiliar de outros a atividade da educação física precisa garantir que de fato, as ações físicas e a noções lógicas matemáticas que a criança usaria nas atividades escolares e fora da escola possam se estruturar adequadamente. (FREIRE, 1994, p. 24)

Nos estudos de Betti (1992,) aparecem três posicionamentos em relação ao papel da educação física na escola: a 
educação física adaptativa, mas ao mesmo tempo hierárquica para funcionamento das aprendizagens no sistema social. Orientação dos objetivos da prática docente em educação física para o corpo, mas principalmente à personalidade dos alunos com metas de funcionamento na esfera cultural, corporal e do movimento. E a educação física para o desenvolvimento de aprendizagens e comportamentos positivos, intelectuais, todos associados à emoção, às conquistas culturais e sociais que se interligam na apreciação corpo e do movimento.

Referindo-se especialmente ao ensino médio, registra-se aqui a proposta dos Parâmetros Curriculares Nacionais que propõe, mesmo antiga, mas não ainda dissonante à realidade didática da educação "[...] um novo conceito de ensino, onde se busca dar significados ao conhecimento escolar, mediante a contextualização, mediante a interdisciplinaridade e incentivando o raciocínio e a capacidade de aprender." (BRASIL, 1999, p.36). Estimular ao raciocínio, livre e criativo é uma proposta ideal à qualquer parâmetro educacional.

Analisando a prática pedagógica da educação física inferida no ensino médio nos PCN's, em Brasil (1999), esse documento aponta como principal objetivo, aproximar o aluno do ensino, de forma lúdica, educativa e contributiva e para consolidação, aprofundamento dos conhecimentos adquiridos no ensino fundamental; para o prosseguimento nos estudos, o preparo para o trabalho e a cidadania, o desenvolvimento de habilidades, como continuar aprender a ser flexível às novas condições de ocupação e aperfeiçoamento, o aprimoramento do educando como pessoa humana, e em todos, se incluindo a ética e o desenvolvimento do intelecto autônomo e do pensamento crítico.

Assim, afirma-se que o papel da educação física no ensino médio é promover ao

[...] desenvolvimento global de cada
aluno, procurando formá-lo como
indivíduo participante; deve visar a
integração desse aluno como ser
independente, criativo e capaz, uma
pessoa verdadeiramente crítica e
consciente, adequada à sociedade em
que vive. (PICCOLO, 1995, p.12).

Para essa função socioeducativa, o educador deve tem abertura às mudanças educacionais, ter compromisso, atender aos anseios do educando, compreendê-lo na sua cultura, no seu corpo e no processo social em que está inserido.

Para primeira abordagem se acredita ter grande possibilidade de orientar o professor em sua prática pedagógica na escola especificamente no ensino médio; essa é a abordagem denominada de concepção aberta no ensino da educação física. Se fundamenta na teoria de Hildebrandt e Laging (1986). A concepção 
aberta do ensino da educação física tem como principal objetivo contribuir à uma mudança no currículo da educação física que conforme Dieckert (1986), devido à formação cultural do Brasil, o ensino do esporte (praticado) nas escolas vêm se mantendo dentro de um currículo fechado. A concepção aberta de ensino crítica ao currículo fechado em algumas características como:

Um planejamento unilateral (onde só professor faz parte dele); Os conteúdos são pré-determinados (modalidade esportiva, jogos, regulamentos e orientação para a competição etc.); Processo de aprendizagem é econômico (transmissão do conhecimento visa a alcance dos objetivos no menor tempo possível); A avaliação é realizada de acordo com a execução correta de gestos técnicos e analisados somente pelo docente. (HILDEBRANDT; LAGING, 1986, p. 5. Grifo do autor).

Se percebe que esta prática é técnica, focada em resultados que convergem para performances físicas. Porém, nesta concepção de ensino a participação dos alunos no planejamento das aulas, na definição dos objetivos, na seleção de conteúdos e na execução das atividades propostas, pode ser descrita por características que Hildebrant E Laging (1986) ser refere como planejamento comum entre os alunos de acordo com o objetivo da ação, ou seja, tem certo autoritarismo curricular. Existe flexibilidade nos conteúdos do esporte praticado, mas se os movimentos o exigirem; neste aspecto a performance determina a flexibilidade do conteúdo, pois ela depende da perfeição do movimento. Há espaço, para ações entre os alunos, com criatividade, comunicação e cooperação, eles passam a serem sujeitos da sua aprendizagem, neste aspecto prevalece o viés competitivo, mas se aproxima de uma cultura pedagógica mais corporativista.

Se percebe que os autores defendem o ensino com a participação dos alunos nas decisões, na orientação dos objetivos, dos conteúdos, da organização, da transmissão e de outros aspectos. Mas sempre presente uma regulação para isso; o efeito é que eles não adquirirem consciência de responsabilidades criativas se não tiver que arcar com a responsabilidades.

Numa concepção aberta solicita-se ao aluno que participe das decisões. Cada decisão do professor pode ser apresentada de tal forma que deixe espaço aberto ou limitado ao aluno, assim, o "grau de abertura." (HILDEBRANDT; LAGING, 1986, p.15), é interdependente das decisões, mas reguladas pelo que o professor gerencia como conteúdo para o aluno. É uma versão clássica da pedagogia tradicional. Exprime sempre uma decisão prévia do professor.

Com relação aos conteúdos, nesta concepção, eles podem ser questionados pelos participantes quanto à importância, devem ser estimulantes e aplicados para fazer jus a área de necessidades subjetivas 
dos alunos. Isto significa que o professor deve tornar os conteúdos aplicáveis, correspondendo aos objetivos. Além disso, cabe ao professor enquadrar os conteúdos no contexto social e organizá-los metodologicamente.

A promoção de processo criativo de reflexão e de ação é outro requisito para o ensino subjetivado. Um método de reflexão é o diálogo de aula com toda a turma ou em pequenos grupos. Nestes processos é necessário que $\mathrm{o}$ professor não deixe explicito, na sua elaboração de tarefas, uma solução previamente determinada, mas que apresente colocações de problemas que estimulem processos de ação divergentes possibilitando inúmeras soluções.

No que diz respeito à avaliação do êxito da aprendizagem, depende-se por um lado dos objetivos da ação dos alunos e por outro das intenções do professor. Não deve existir uma ausência da avaliação daquilo que aconteceu quanto a ação das aulas, onde se reflete a própria prática, por ser preciso se pensar na continuidade processo.

Sendo assim, a avaliação é convencionada à prática predeterminada pelos docentes, em um "[...] conjunto concreto nas tarefas, temas, questões, e arranjos de aparelhos. Os alunos devem avaliar subjetivamente seu êxito (resultado) no processo de ensino e julgá-lo" (HILDEBRANDT; LAGING, 1986, p.44.grifo do autor).
Outra abordagem é a críticosuperadora, essa abordagem foi construída a partir do trabalho "[...] metodologia do ensino da educação física." (FILHO, et. al. 1992, p.86). Esta defende uma proposta crítica de educação física, a partir de uma análise das estruturas de poder e dominação existente em nossa sociedade. Trabalha com o conceito de cultura corporal, que se opõe ao conceito de aptidão física enquanto objetivo final da disciplina e propõe o trato com conhecimento em forma de ciclos de escolarização. Portanto, não se trata de aprender o jogo pelo jogo, o esporte pelo esporte, mas esses conteúdos recebem um tratamento metodológico, para que possam ser aprendidos em sua totalidade, "enquanto conhecimentos construídos culturalmente, e ainda recebem uma interpretação crítica da realidade que envolve o aluno." (FILHO, et.al, 1998, p.15).

Para alcançar esses objetivos, é necessário superar a ênfase na aptidão física, no desporto de rendimento $\mathrm{e}$ caracterizar a educação física de forma mais abrangente, incluindo todas as dimensões do ser humano envolvidas em cada prática corporal. Enfim, compreender a educação física como disciplina que introduz e integra ao aluno na cultura corporal de movimento, assim " [...] formando um cidadão que vai produzi-la e transformá-la, instrumentalizando-o para usufruir os jogos, dos esportes e das danças em 
benefício de sua qualidade de vida. Nessa concepção dá-se ênfase aos aspectos socioculturais." (BONONE, 2000, p.27).

Uma terceira abordagem, conhecida como crítico-emancipatória, conforme Azevedo, (2001) defende que o aluno deva ser capacitado para sua participação na vida social, cultural e esportiva, o que torna necessária não apenas a capacidade da ação funcional, como também a capacidade de conhecer, reconhecer e problematizar sentidos de significados através da flexão crítica. Diz, também, que a capacidade comunicativa não é algo dado pela natureza, mas deve ser desenvolvida.

O autor dessa teoria conforme Kunz (1994) orienta à compreensão do esporte nos seus múltiplos sentidos e significados para nele agir com autonomia e liberdade e, com isso, "[...], além da capacidade objetiva, efetivamente praticar o esporte e ainda integrar-se socialmente através da comunicação.” (KUNZ, 1994, p.34). Ela sugere a análise crítica do esporte, defende que devem ser oferecidas oportunidades de tematizar o esporte de várias maneiras. Deve ser um ensino móvel que se altera entre dinamicamente em suas relações metodológicas.

Uma outra abordagem denominada de sistemática defende que sociedade possui um sistema adaptativo complexo, caracterizado pela capacidade de persistir e desenvolver-se, modificando a própria estrutura. Acredita que a sociedade responde as necessidades de mudança, adaptando sua estrutura e reequilibrando-se em nível maior de complexidade. Concebe a educação física como um sistema adaptativo, complexo, hierárquico e aberto, segundo Mosston (1978). A análise sistêmica propõe a entrar no interior do processo ensino-aprendizagem, na prática propriamente dita, no relacionamento professor-aluno-matéria de ensino.

A abordagem sistemática considera o processo ensino-aprendizagem em educação física como um ato de tomada de decisões conjuntas entre professores e alunos. Elaborada por Mosston (1978), sugere na relação professor aluno, haver uma sucessão acumulativa de decisões, de soluções referentes a opções conhecidas. Os alunos, por sua vez receberão as influências das decisões tomadas pelos professores, alterando o comportamento deles. "As decisões do professor são tomadas como base na sua formação cultural, os seus defeitos, nas limitações pessoais e nas suas concepções filosóficas e pedagógicas." (SHIGUNOV, 2001, p. 45).

Diante dessas abordagens percebese que "[...] existem muitas possibilidades que podem ser bem-exploradas por aqueles profissionais atentos e que realmente estão interessados no bem-estar de seus alunos, tanto no presente como no futuro." (SHIGUNOV, 2001, p.33). Estes 
profissionais devem ser criativos, pois um estudo monótono sempre tem a chance de ser rapidamente abandonado pelo estudante. Isso vale também para a educação física no ensino médio. Que a maioria dos alunos são apáticos às atividades físicas. Ao pensar no porquê dessa apatia com relação à aula de educação física, encontra-se a resposta na estrutura do currículo, nas práticas repetitivas, na unilateralidade das propostas de aula e na falta de criatividade dos professores.

Discutir os conteúdos a serem trabalhados também é uma forma de sociabilizar, aprendizagem entre os próprios alunos, desenvolvendo-se assim uma postura política de aceitação dos resultados a serem definidos pela maioria. Além disso, o aluno participa do processo de formação daquilo que irá ser dito em aula, dando mais valor aos conteúdos que foram construídos por ele mesmo junto com seus colegas, tornando-se um agente do seu próprio conhecimento e não apenas um receptor de informações, ficando autônomo para escolher e percebendo a importância de sua participação na construção e transformação do processo ensinoaprendizagem.

Sobre a educação física no ensino médio, Darido (2001) apresenta algumas considerações apontando a obra de Daólio (1986) que discutiu a importância da educação física para o aluno trabalhador.
[...] autor procurou levantar a importância da educação física para o adolescente que trabalha numa perspectiva psicológica. Embora não tenha se referido ao ensino médio especificamente o seu trabalho permite discuti-lo uma vez que, as maiorias dos alunos do ensino médio são trabalhadores. (DARIDO, 2001, p.61).

Conforme Darido (2001) apresenta uma proposta para a educação física no ensino médio através da coordenadoria de normas pedagógicas (CENP). Neste documento,

Levantam as características do desenvolvimento dos adolescentes sob o enfoque cultural, cognitivo, afetivo e físico. Em seguida, apresenta uma proposta metodológica em que os desafios sejam sempre provocados, como exemplo citam as táticas esportivas que podem ser colocados em forma de problema para os alunos responderem. Em termos de conteúdos para o ensino médio sugerem que a educação física valorize a contextualização histórica do esporte em nível teórico e a aprendizagem para além do esporte, como por exemplo, a dança. (DARIDO, 2001, p. 62-3).

Darido (2001) infere a Correia (1996), informando que ele comenta a educação física no ensino médio partir da ideia de um planejamento participativo por possuir algumas vantagens atreladas à participação voluntária dos alunos nas atividades, incentivados à valorizar a disciplina, se engajar e se engajar em equipes neste desempenho. 
Acerca das desvantagens, afirma Darido (2001) que Correia (1996) considera haver maior planejamento do professor, exige maior condição de controle de turma, flexibilidade de metodologias, exigência de recursos e gerenciamento de discussões. $\mathrm{Na}$ continuidade de análise Darido (2001) infere o trabalho de Melo (1997) que considera a importância em ser oferecida uma diversidade a atividades aos alunos, de modo inovador e menos tradicional corroborando que Melo (1997)

[...] implementou um programa de educação física para o ensino médio utilizando jogos. Entre eles; diferentes tipos de queimadas, hand sabonete, pic bandeira, quatro cantos, e outros. Ao fim do programa os alunos avaliaram positivamente o programa e ressaltaram que estes conteúdos devem estar disponíveis também nas aulas regulares de educação física. (DARIDO, 2001, p.64).

Essa variedade de atividades é defendida pela maioria dos autores que Darido (2001) estuda. Verenguer (1995), para ela, esse autor procura abordar a formação do professor de educação física que trabalha no ensino médio. Nesse sentido aponta Nahas (1997) que sugere a função da educação física para o ensino

\section{CONSIDERAÇÕES FINAIS}

Pensa-se que o caminho em busca de uma educação física mais significativa para o ensino médio e que seja atraente para o médio ser a educação para um estilo de vida ativo; Referindo-se a Tedeschi (1997) observa que este apresenta um relato de experiências de uma escola particular de São Paulo fundamentada na proposta crítico-superadora. Segundo Filho et. al. (1992).

Costa (1997) ressalta acreditar que os alunos nesta faixa etária (ensino médio), possuem uma opinião formada sobre a educação física fundamentada em suas experiências pessoais anteriores. Ao que Darido (2001) discorre, serem experiências prazerosas, sem exclusão, motivadoras, técnicas, mas com abertura metodológica consistente na participação dos alunos.

Estas reflexões sobre as possibilidades de abordagens pedagógicas para o ensino da educação física no ensino médio também refletem dificuldades no sentido o sentido e significado no jeito de atuar percebem-se as dificuldades de se trabalhar com educação física no ensino médio, porém acredita-se que seja possível implementar propostas que apresentem praticas interventivas diferenciadas para a educação física na escola, como foi registrada nessa análise.

aluno e ao mesmo tempo satisfaça profissionalmente os professores e a sociedade. Nisto a educação física no ensino médio passou por uma ampla discussão acerca dos objetivos, conteúdos, 
métodos, posturas e currículo. Esta disciplina tem um papel abrangente na comunidade escolar e, portanto, necessita de muito estudo zelo e atenção para que se possa cumprir todos papeis a que se propõe sejam eles somente de caráter biológico, ou mais amplo, incluindo o social.

Esta análise sobre a educação física converge em grande valia por ser pesquisada e contribuir à ampliação da fundamentação pedagógica nesse nível de ensino, o médio. Porém, longe de assumir "verdades absolutas", e sim desafiar novas

\section{REFERÊNCIAS}

AZEVEDO, E. S: Reflexões sobre as abordagens pedagógicas em Educação Física. Londrina: Midiograf, 2001.

BETTI, Mauro. Educação Física e Sociedade. São Paulo: Movimento,1992.

BONONE, Carlos, GABRIEL, Gallina. A Prática da a Educação Física n Escola. Porto Alegre: UFRGS, 2000.

BRASIL, Parâmetros Curriculares Nacionais: Educação Física. Brasília: Secretaria de Ensino Médio. MEC/SEF, 1999.

COSTA, C.M. Educação Física diversificada, uma proposta de participação. Anais do IV Seminário de Educação Física Escolar/ Escola de Educação Física e Esporte, p. 47, 1997.

DARIDO, Suraya Cristina. GALVÃO, Zenaide. FERREIRA, Lilian Aparecida. pesquisas, que venham a contribuir com práticas inovadoras para educação física é preciso o aluno estar à frente de suas decisões $\mathrm{s}$ formulações cognitivas de aprendizagem, serem conduzidos à formalidade, mas sem desprezar sua criticidade e poder de decisão, independente das disciplinas e conteúdos. É necessário mudar e refletir ousar e principalmente tentar de alguma forma conduzir a educação física ao desempenho do seu verdadeiro papel na escola.

FIORIN, Giovanna. Educação física no ensino médio: reflexões e ações. MOTRIZ - Volume 5, Número 2, Dezembro/1999. Disponível em: <http://www.rc.unesp.br/ib/efisica/motriz/ 05n2/5n202Darido.pdf $>$. Acesso em: 24/05/2020.

CORREIA, Walter Roberto. Planejamento Participativo e o Ensino de Educação Física no $2^{\circ}$ grau.1996. Disponível em: $<$ Rev. paul. Educ. Fís., São Paulo, supl.2, p.43-48,1996. Disponível em:<https://www.revistas.usp.br/rpef/articl e/download/139647/134938/>Acesso em: 24/05/2020.

DAÓLIO, J. A importância da educação física para o adolescente que trabalha: uma abordagem psicológica. Revista Brasileira de Ciências do Esporte - v.8 - n.1 - 1986 Campinas, 1986. Disponível em:<http://cev.org.br/biblioteca/aimportancia-educacao-fisica-para-oadolescente-que-trabalha-uma-abordagempsicologica/>. Acesso em: 20/05/2020.

DARIDO, S. C. Os conteúdos da Educação Física escolar: influências, tendências 
dificuldades e possibilidades. Perspectivas em Educação Física Escolar. Perspectivas em Educação Física Escolar - v.2 - n.1 2001 Niterói, 2001. Disponível em:<http://cev.org.br/biblioteca/osconteudos-educacao-fisica-escolarinfluencias-tendencias-dificuldadespossibilidades/>. Acesso em: 24/05/2020.

Suraya Cristina. Educação

Física na Escola: questões e reflexões. Rio de Janeiro, RJ\; Guanabara Kogan, 2003.

DIECKERT, Juergen et al. Elementos $e$ Princípios da Educação. 1. Ed. Rio de J Janeiro: ao livro técnico, 1986.

FILHO, Lino Castelani. Política Educacional e Educação física. Campinas, SP: Autores associados, 1998.

FREIRE, Paulo. Uma Escola Chamada Vida. 8ed. Cortez. São Paulo,1994.

GIROUX, Henry. Teoria Crítica e Resistencia em Educação: para além das teorias de reprodução. Petrópolis: Vozes, 1986.

HILDEBRANDT, Stramann Reiner. Textos pedagógicos sobre ensino da Educação Física. Rio Grande do Sul: Ed. Unijuí, 2003.

HILDEBRANDT-STRAMANN, R.; LAGING, R. Concepções abertas no ensino da Educação Física. Rio de Janeiro: Ao Livro Técnico, 1986.

MELO, V. A. Porque devemos estudar História da Educação Física/Esportes nos cursos de graduação. Motriz - v.3 - n.1 1997.1997. Disponível em:

<http://www.scielo.br/scielo.php?script=sc i_serial\&pid=1980-

$6574 \& \operatorname{lng}=\mathrm{pt} \& \mathrm{nrm}=\mathrm{iso}>$. Acesso em: 24/05/2020.

MOSSTON, M. La enseñanza de la Educación Física- Del Comando al descobrimento. Buenos Aires: Paidos, 1978.

NAHAS, M. V. Educação Física no ensino médio: educação para um estilo de vida ativo no terceiro milênio. Anais do IV Seminário de Educação Física Escolar/ Escola de Educação Física e Esporte, p.17-20, 1997. In:DARIDO, Suraya Cristina. GALVÃO, Zenaide. FERREIRA, Lilian Aparecida. FIORIN, Giovanna. Educação física no ensino médio: reflexões e ações. MOTRIZ - Volume 5, Número 2, Dezembro/1999. Disponível em: < http://www.rc.unesp.br/ib/efisica/motriz/05 n2/5n202Darido.pdf > Acesso em: 24/05/2020.

KUNZ, Elenor. Transformação DidáticoPedagógico do Esporte. Ijuí: Unijuí, 1994. PICOLLO, Vilma N. (org.). A Educação Física Escolar: ser ...ou não ter? Campinas, SP: Unicamp, 1995.

SHIGUNOV, Victor; SHIGUNOV NETO, P; ALEXANDRE (ORG). A Formação Profissional e a Pedagogia: Ênfase nos professores da Educação Física. Londrina: Midiograf, 2001.

Victor; SHIGUNOV NETO,

Alexandre. Educação Física

Conhecimento Teórico / Prática

Pedagógica. Porto Alegre: Ed. Mediação, 2002.

SOARES, Carmem Lucia; TAFFAREL, Celia n. Zulke; VARJAL, Elizabeth et al. Metodologia do Ensino de Educação Física. São Paulo: Cortez,1994.

SOARES, Lúcia, ZÜLKE, Celi Nelza. VARJAL, Maria Elizabeth Medicis Pinto. FILHO Lino Castellani. ESCOBAR, Micheli Ortega. BRACHT, Valter. Coletivo De Autores. Metodologia do Ensino de Educação Física. São Paulo: Cortez,1992. 
SOUZA JUNIOR, Marcílio. Educação Física Rumo a Um Novo Conhecimento: uma experiência com discentes da $4^{\mathrm{a}}$ serie. Corporis, n. 2, 1997. [Online]. Disponível em: < www.URL:upe.br.corporis2artigo5html $>$. Acesso em: 20/05/2020.

TEDESCHI, S. M. Educação Física escolar: relatos e propostas. Anais do IV Seminário de Educação Física Escolar / Escola de Educação Física e Esporte, p.3446, 1997. In: DARIDO, Suraya Cristina. GALVÃO, Zenaide. FERREIRA, Lilian Aparecida. FIORIN, Giovanna. Educação física no ensino médio: reflexões e ações. MOTRIZ - Volume 5, Número 2, Dezembro/1999. Disponível em: <http://www.rc.unesp.br/ib/efisica/motriz/ 05n2/5n202Darido.pdf $>$. Acesso em: 24/05/2020.

VERENGUER, R.C.G. Educação Física escolar: considerações sobre a formação profissional do professor e o conteúdo do componente curricular no $2^{\circ}$ grau, Rev. paul. EducJFls., São Paulo, 9(1): 69-74, jan a Jun. 1995. Disponível em:<http://www.revistas.usp.br/rpef/article /viewFile/139420/134756 > Acesso em: 24/05/2020.

WERNECK, Halmilton. Se você finge que ensina, eu finjo que aprendo. 19 ed.

Petrópolis, RJ: vozes, 1992. 